\title{
Hogar seguro: protección financiera familiar que subordina provisionalmente el interés económico de acreedores, propietarios y herederos
}

Edwin R. Maldonado Medina

Universidad de Puerto Rico, Río Piedras

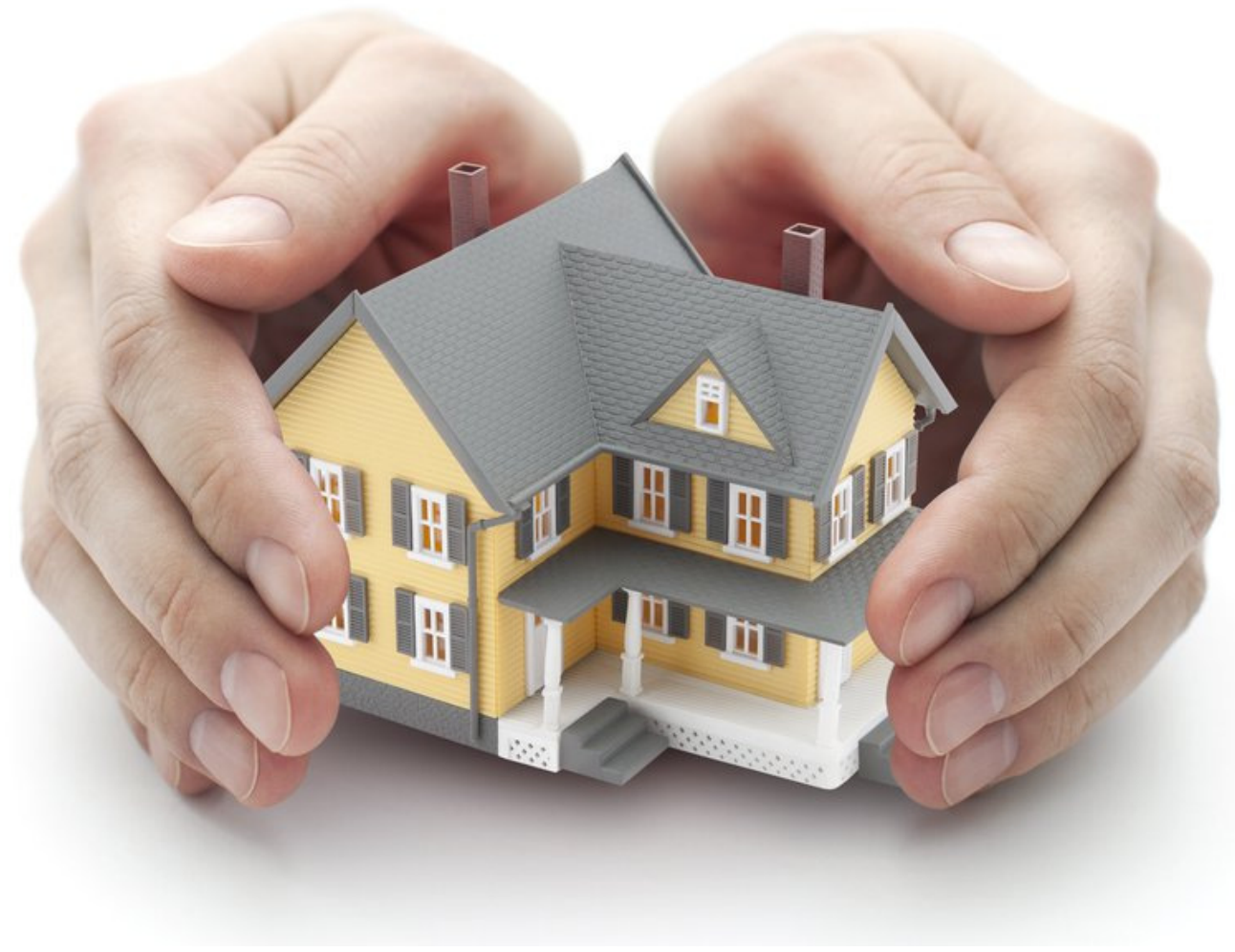

\section{RESUMEN}

La figura de hogar seguro fue modificada por legislación aprobada en el año 2011. Por más de un siglo, el hogar seguro ha intentado proteger la residencia principal de un individuo o grupo familiar al (1) establecer un valor máximo de la residencia protegido contra embargos y (2) proveer el derecho de poseer y disfrutar una residencia de forma exclusiva por tiempo determinado en casos de divorcio, separación o muerte. La nueva legislación elimina el valor máximo protegido contra embargos y establece que la residencia estará libre de ejecución. Sin embargo, el estatuto indica que el sector hipotecario, el gobierno y contratistas bajo ciertas circunstancias podrán ejecutar la residencia para el cobro de una deuda. Por consiguiente, el nuevo estado de derecho al intentar proteger a ciertos dueños de residencias y acreedores logra simultáneamente desplazar a un segundo plano a otras personas con intereses económicos sobre una residencia.

\section{PALABRAS CLAVES}

Hogar seguro, familia, acreedor, propietario, heredero, planificación 


\section{Introducción}

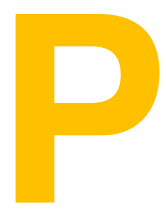

ocas veces tenemos la oportunidad de evaluar una figura jurídica del ámbito familiar que tiene un impacto económico en personas ajenas al hogar. En el 2011 se aprobó la Ley del Derecho a la Protección del Hogar Principal y el Hogar Familiar con el propósito de establecer los procedimientos para evitar el embargo y la ejecución de la residencia principal de una familia por parte de acreedores. Esta ley establece unos beneficios de vanguardia al aumentar la cantidad por la cual el hogar de un jefe de familia queda protegido ante una acción de cobro de dinero. Sin embargo, la protección que brinda esta pieza legislativa a la familia conlleva un costo económico para ciertos acreedores, propietarios del hogar protegido y hasta herederos con participación en dicha propiedad.

Parte del análisis realizado presenta la evolución legislativa del derecho a hogar seguro en Puerto Rico. Posteriormente, se estudian las limitaciones y excepciones establecidas en la nueva ley cuando los acreedores llevan acciones de cobro de dinero contra la residencia de una familia. Finalmente, se evalúa cómo la ley y la jurisprudencia han colocado en menor jerarquía cualquier interés propietario sobre el hogar seguro afectando provisionalmente la venta o enajenación de dicha propiedad.

Por consiguiente se aprobó la Ley 195 de 2011 con el propósito de ampliar significativamente la protección de las residencias de los ciudadanos. Esta ley, diferente de las leyes anteriores, evita la ejecución total de la residencia y permite que su dueño y familia posea pacíficamente la propiedad dentro de un término establecido por ley. Muy distinto del procedimiento bajo la ley anterior que permitía al acreedor vender la residencia del deudor y del producto de la venta entregarle a éste solamente $\$ 15,000$ para la adquisición de una nueva propiedad. Claramente dicha cantidad dejó de ser un monto viable para adquirir una residencia.

Un examen de la ley nos permite observar el alcance de esta nueva legislación. Primeramente, la exposición de motivos indica como fundamento para la creación de la pieza legislativa brindar una mayor protección económica del hogar y dictar las reglas para proteger el derecho a hogar seguro de las ventas promovidas por acreedores en virtud de sentencia $o$ ejecución. Además, la exposición de motivos aclara que la protección que la Ley provee de "ninguna manera restringe el derecho a hogar seguro que en los casos de divorcio se concede a uno de los cónyuges por razón de adjudicársele la custodia de los hijos, según dispone el Artículo 109 A del Código Civil de Puerto Rico, Ley Núm. 184 de 26 de diciembre de 1997."

A su vez, el Artículo dos (2) establece que es política pública del gobierno de Puerto Rico "asegurar que todo individuo o jefe de familia domiciliado en Puerto Rico, goce de una protección que cobije la posesión y el disfrute de su residencia principal contra el riesgo de ejecución de esa propiedad." El Artículo tres (3) expone que "Todo individuo o jefe de familia, domiciliado en Puerto Rico, tendrá derecho a poseer y disfrutar en concepto de hogar seguro, una finca consistente en un predio de terreno y la estructura enclavada en el mismo, o una residencia bajo el régimen de la Ley de Condominios que le pertenezca o posea legalmente, y estuviere ocupado por éste o por su familia exclusivamente como residencia principal." 
Además, el Artículo cinco (5) indica que "este derecho protege a la propiedad de embargo, sentencia o ejecución para el pago de todas las deudas, excepto las deudas reconocidas como excepciones en el Artículo cuatro (4) de esta Ley." El Artículo seis (6) establece que la protección de hogar seguro "subsistirá después de la muerte de uno de los cónyuges a beneficio del cónyuge supérstite mientras éste continúe ocupando dicho hogar seguro, y después de la muerte de ambos cónyuges a beneficio de sus hijos hasta que el menor de éstos haya alcanzado la mayoría de edad." Abunda el Artículo seis (6) al indicar que "Cuando se trate de persona no casada, pero jefe de familia por razón de depender de ella para su subsistencia, sus ascendientes o descendientes hasta el tercer grado de consanguinidad o de afinidad, la protección subsistirá después de la muerte de aquella a beneficio de sus indicados familiares mientras éstos continúen ocupando dicho hogar seguro, y hasta tanto que el menor de dichos dependientes haya llegado a la mayoría de edad." Finalmente, la protección de hogar seguro no tiene que estar inscrita en el Registro de la Propiedad a tenor con el Artículo once (11) de la Ley, pero, es altamente recomendable para establecer una divulgación oportuna a terceros.

Un análisis consolidado de los artículos antes señalados nos indica que la intención del legislador es que la residencia principal de una persona no pueda ser embargada o ejecutada mientras la misma tenga la protección de hogar seguro. Esta protección tendrá vigor durante la vida del titular de la residencia y, de estar casado, la protección continuará posterior a su muerte a favor del cónyuge supérstite y de sus hijos hasta que el menor de éstos alcance la mayoría de edad. Por tanto, este nuevo estatuto brinda una protección mucha más amplia que la ley anterior la cual permitía la ejecución de la propiedad siempre y cuando se le entregara al dueño la cantidad máxima de $\$ 15,000$.

Sin embargo, la protección de hogar seguro tiene sus excepciones. El Artículo cuatro (4) de la Ley expone que, aunque el hogar seguro es irrenunciable, se entenderá que el dueño de una residencia principal lo ha renunciado en las siguientes circunstancias: (a) en todos los casos donde se obtenga una hipoteca, que grave la propiedad protegida, (b) en los casos de cobro de contribuciones estatales y federales, (c) en los casos donde se le deban pagos a contratistas para reparaciones de la propiedad protegida, (d) en los casos donde aplique el Código de Quiebras Federal, y (e) en todos los casos de préstamos, hipotecas, contratos refaccionarios y pagarés constituidos a favor de $\mathrm{o}$ asegurados $\mathrm{u}$ otorgados por ciertas agencias estatales $y$ federales, descritas en la ley, que garanticen préstamos hipotecarios que se aseguran y se venden en el mercado secundario. Por consiguiente, aquel individuo que incumpla con cualquier obligación que surja de las circunstancias antes indicadas, la protección de hogar seguro no le aplicará con la consecuencia que su residencia se podrá embargar y ejecutada para el cobro de la deuda.

A tenor con lo antes indicado, podemos observar que el derecho a hogar seguro protege la residencia principal de una familia ante el embargo y ejecución de acreedores excepto en aquellos casos excluidos por la Ley. Sin embargo, esta protección familiar revestida de un incuestionable interés social conlleva la postergación $\mathrm{o}$, inclusive, eliminación de ciertos derechos en algunas personas naturales o jurídicas como presentamos a continuación. 
Efectos en los procedimientos de cobro de dinero ejecutarse mediante autorización del Tribunal, a moción de parte y previa notificación a todas las partes." Por consiguiente, la regla general es que todo acreedor con una sentencia final $y$ firme podrá ejecutar la misma mediante el embargo y venta de las propiedades del deudor. protección es irrenunciable, verán

limitado su derecho a ejecutar una

sentencia sobre una residencia

principal debidamente protegida. tenor con el Artículo cuatro (4) de la Ley, y (b) aquellos acreedores cuyo crédito se afecta debido a que la protección de hogar seguro es irrenunciable. Estos parámetros establecidos por la Ley sobre la renuncia del Hogar Seguro amplían grandemente los beneficios para ciertos acreedores mientras que, para otros, los limitan considerablemente. Analicemos ambos grupos de acreedores.

En los casos que un acreedor cuyo crédito sin garantía se torna incobrable, generalmente recurre a una acción legal de cobro de dinero contra el deudor. Cuando el tribunal emite la sentencia, ocasionalmente el deudor realiza el pago adeudado. Sin embargo, en aquellos casos donde no se logra el cobro posterior a la sentencia, el acreedor puede recurrir a ejecutar la misma a través del procedimiento establecido en la Regla 51.1 de Procedimiento Civil, 32 L.P.R.A. Ap. V (2009) la cual dispone que "la parte a cuyo favor se dicte sentencia podrá ejecutarla mediante el procedimiento fijado en esta Regla 51, en cualquier tiempo dentro de cinco (5) años de ésta ser firme. Expirado dicho término, la sentencia podrá
Sin embargo, a manera de excepción, los acreedores cuyos deudores disfrutan de la protección de hogar seguro, debido a que dicha protección es irrenunciable, verán limitado su derecho a ejecutar una sentencia sobre una residencia principal debidamente protegida. Ahora bien, esta limitación no es absoluta ni permanente. En primera instancia, el acreedor no podrá ejecutar la cualquier otro bien mueble o inmueble perteneciente al mismo, a menos que sean bienes no embargables por disposición de ley. Segundo, la Regla 51 le provee un término al acreedor para que ejecute la sentencia. Si dicho término expira y el deudor aún disfruta de la protección de hogar seguro, dicha residencia escapa totalmente de la ejecución. Sin embargo, si la protección de hogar seguro termina previo a que expire el término para ejecutar, entonces, el acreedor podrá embargar y ejecutar la residencia familiar para cobrar su crédito.

Por el contrario, en los casos donde el hogar seguro se entiende renunciado, el acreedor podrá cobrar su crédito mediante el embargo y ejecución de las propiedades del deudor incluyendo su residencia principal. residencia principal del deudor, pero sí 
Por tanto, los acreedores hipotecarios, las agencias de gobierno federal y estatal encargadas del cobro de impuestos, los contratistas de obras sobre la propiedad protegida, la Corte de Quiebras Federal y agencias que garantizan préstamos hipotecarios podrán embargar y ejecutar el hogar familiar debido a que su titular renunció a la protección de hogar seguro. Cabe señalar que el deudor no tiene que realizar la renuncia expresamente por escrito como requería la ley anterior en los casos aplicables. Simplemente, la Ley indica que el hogar seguro se entenderá renunciado en las circunstancias que expresa su Artículo cuatro (4). Por ejemplo, bajo la ley anterior, un acreedor hipotecario incorporaba una cláusula en la escritura de hipoteca sobre renuncia al hogar seguro al gravar una propiedad protegida. De esta forma, el deudor hipotecario renunciaba a su hogar seguro. Sin embargo, bajo la nueva legislación el acreedor hipotecario está protegido $a b$ initio debido a que por el mero hecho de extender el crédito hipotecario, el hogar seguro se entiende renunciado sin la necesidad de expresarse en la escritura. No obstante, es altamente recomendable que el notario de la escritura de hipoteca instruya y advierta al deudor hipotecario sobre su renuncia al hogar seguro por el mero hecho de asumir la hipoteca.

En resumen, podemos observar cómo se limitan los derechos de unos acreedores mientras otros resultan favorecidos. En los casos donde el hogar seguro se entiende renunciado el estado protege directamente a la industria bancaria, acreedores hipotecarios y aquellas entidades que garantizan préstamos hipotecarios. Por otro lado, cuando la figura del hogar seguro es aplicable, simplemente los acreedores se ven impedidos de cobrar un crédito otorgado a un jefe de familia mediante el embargo de uno de sus mayores activos: su residencia.

\section{Derecho de propiedad subordinado al interés social}

Aquella persona que posea un interés propietario sobre una residencia protegida por la ley de hogar seguro tendrá su derecho de dominio afectado provisionalmente debido a que esta ley crea limitaciones en la posesión y disposición de dicho activo. Entre los distintos propietarios que puede tener una residencia familiar se encuentran individuos, cónyuges y miembros de una comunidad de bienes incluyendo herederos. En un análisis de nuestro tribunal supremo a la pieza legislativa de hogar seguro de 2003, supra, la mayoría estableció que dicha ley posee dos aspectos medulares. "En primer lugar, esta ley crea un derecho de poseer $\mathbf{y}$ disfrutar, en concepto de hogar seguro, una "finca", en los términos dispuestos en su Sección 1, siempre y cuando la misma le pertenezca a una persona jefe de familia, o la posea legalmente, y que esté ocupada por dicha persona, o su familia, como residencia. En segundo lugar, la legislación crea una exención que opera en contra de terceros acreedores y a favor del jefe de familia, para así proteger la vivienda familiar de embargos, sentencias, entre otros." Rodríguez Ramos v. Pérez Santiago, 161 D.P.R. 637, 648 (2004). Por tanto, el tribunal entendió que el espíritu de la legislación de hogar seguro de 2003, similar a la Ley de 2011, además de proveer protección contra acreedores, reconoce el derecho de un jefe de familia de poseer y disfrutar de una propiedad como su hogar. Además, el Tribunal reconoce que la protección al hogar familiar que se provee en los casos de divorcio es producto del amplio tema de hogar seguro. Que, previo a la creación del Artículo 109 A del Código Civil, el Tribunal hacía referencia a la Ley de hogar seguro vigente para establecer la protección a la residencia familiar mediante 
equidad. En conclusión, quien posea un interés propietario sobre una residencia protegida por la Ley, pero no sea jefe de familia, estará impedido de realizar actos de posesión y/o enajenación de dicha propiedad. Veamos.

Los cónyuges, como regla general, pueden vender, hipotecar o enajenar su residencia principal. La mayor limitación que puede tener un matrimonio mientras subsista la sociedad de bienes gananciales, es el requisito de anuencia de ambos cónyuges para disponer de bienes inmuebles de la sociedad, de lo contrario la transacción es nula, 31 L.P.R.A. \$284. Ahora bien, el Artículo seis (6) de la Ley nos indica que en los casos donde uno de los cónyuges abandone a su familia, la protección de hogar seguro "continuará a favor del cónyuge que ocupe la propiedad como residencia; y en caso de divorcio el tribunal que lo conceda deberá disponer del hogar seguro según la equidad del caso." Por consiguiente, aquel hombre o mujer que termine siendo el jefe de familia luego del abandono o divorcio, su hogar estará protegido por la Ley. El otro cónyuge que abandonó el hogar, además de perder la posesión del inmueble, no podrá vender o disponer de su interés propietario en la residencia de la familia hasta que el menor de los hijos haya alcanzado la mayoría de edad. El tribunal supremo ha establecido esta norma al expresar que "la preservación del hogar seguro familiar para el beneficio del grupo formado por madre e hijos tiene primacía sobre el derecho de propiedad del cónyuge en los activos de la disuelta sociedad de gananciales y, por ello, se le atribuyó el uso de dicha propiedad al jefe de familia." Cruz v. Irizarry, 107 D.P.R. 655 (1978). Por tanto, "la propiedad ganancial que constituye el hogar seguro no estará sujeta a división mientras dure cualesquiera de las condiciones en virtud de las cuales se concedió." Rodríguez Ramos V. Pérez Santiago, supra. Es interesante señalar que la propiedad que constituya la residencia de la familia puede ser un bien inmueble privativo de aquel individuo, padre o madre, que abandonó el hogar, limitando su derecho a vender o enajenar dicha propiedad. Vargas v. Muñiz, 171 D.P.R. $530 \quad \frac{\text { (2007). }}{}$ Entendemos por esta decisión, que una propiedad que constituya el hogar de unos hijos producto de una relación extramarital puede disfrutar de la protección de hogar seguro debido a que "el interés propietario del padre tiene que tomar un segundo plano frente a lo que es el mejor bienestar de sus hijos." Vargas v. Muñiz, supra. El tratadista de derecho sucesoral, el doctor Efraín González Tejera, apoya este argumento al señalar que "al fallecer el jefe de familia, su cónyuge viudo o su concubino o concubina y los hijos que con ellos vivían continuarán disfrutando el hogar seguro, hasta que el menor de los hijos llegue a la mayoría de edad." (Énfasis Suplido) Efraín González Tejera, Derecho de Sucesiones, Tomo 1: La Sucesión Intestal, 361-362 (2001).

Por otro lado, la Ley indica en su Artículo seis (6) que la protección de hogar seguro subsistirá después de la muerte de uno de los cónyuges a beneficio del cónyuge supérstite mientras éste continúe ocupando dicho hogar, y después de la muerte de ambos cónyuges a beneficio de sus hijos hasta que el menor de éstos haya alcanzado la mayoría de edad. Esta regla será de igual aplicación para aquellos solteros jefes de familia por razón de depender de ellos para su subsistencia ascendientes o descendientes, mientras éstos ocupen el hogar seguro. Sin embargo, esta legislación provoca un choque entre el derecho de los herederos de realizar la partición del caudal $y$ el derecho del jefe de familia de permanecer en el hogar seguro. 
Puede ocurrir que una propiedad del causante advenga el hogar seguro de su familia. Sin embargo, dicho causante podría tener otros herederos los cuales por disposición de ley son ahora dueños en común proindiviso del hogar protegido. En tal caso, el Código Civil de Puerto Rico establece en su Artículo 1005 que "ningún heredero podrá ser obligado a permanecer en la indivisión de la herencia, a menos que el testador prohíba expresamente la división. Esta prohibición no alcanzará a los bienes que constituyen la legítima de los herederos." 31 L.P.R.A. \$2871. A tenor con este estatuto, un heredero podría intentar reclamar el pago de su participación hereditaria en la residencia considerada hogar seguro.

Dicha controversia se trajo a la atención del tribunal apelativo de Puerto Rico en el caso López Pagán v. Rodríguez Rivera, Caso Número KLAN200701813, Región Judicial de Ponce. En este caso, un hijo mayor de edad del causante, demandó a la viuda del difunto y madre de dos hijos menores y solicitó la liquidación de la comunidad hereditaria. El tribunal, al evaluar la controversia, determinó que tanto el hijo mayor, la viuda y los menores todos pertenecían a una comunidad de bienes hereditarios. Por tal razón, las determinaciones recogidas en la opinión del tribunal supremo en el caso de Vargas $\mathrm{v}$. Muñiz, supra, eran de aplicación al caso ante su atención. Dicho caso impide la venta o enajenación del hogar seguro que a su vez pertenece a una comunidad de bienes creada luego de un divorcio. Por tanto, el tribunal apelativo determinó que el heredero no le asistía el derecho a promulgar la venta del hogar seguro de la madre y sus hijos para cobrar su participación en la comunidad hereditaria toda vez que "la propiedad es un derecho supeditado a intereses superiores de la comunidad y al bien común." Inclusive, se enfatizó que la prohibición recae solamente en la propiedad protegida y no en el resto de los bienes del caudal legítimamente disponibles para la partición del caudal. Se entiende que, aunque esta decisión no establece precedente en nuestra jurisdicción por emitirse en un tribunal apelativo, es altamente persuasiva y se coincide con la decisión del tribunal. A su vez, el doctor Efraín González Tejera, nos indica sobre este punto que "el hogar seguro pasa al cónyuge supérstite que continúe ocupándolo al morir su consorte, de manera que lo recibe el viudo o la viuda por disposición de esta ley, independientemente de los derechos hereditarios de las partes." Efraín González Tejera, Derecho de Sucesiones, Tomo 1: La Sucesión Intestal, 361-362 (2001). Por tanto, a tenor con el espíritu de la Ley y la jurisprudencia actual, es forzoso concluir que los derechos hereditarios sobre una residencia quedan en suspenso mientras la propiedad disfrute de la protección de hogar seguro.

\section{Conclusión}

La política pública de proveer protección al hogar de todos los domiciliados en Puerto Rico y sus respectivas familias es sin duda un principio de justicia apoyado en la equidad. Por tanto, el derecho a hogar seguro resulta en una herramienta indispensable en la planificación financiera y sucesoral al proveer un freno contra acreedores, titulares y herederos que deseen disponer de la propiedad para ejercer cualquier derecho o reclamo que puedan tener sobre el inmueble. Sin embargo, esta protección está limitada en los casos donde el hogar seguro se entiende renunciado. Por tanto, en préstamos hipotecarios, deudas contributivas y casos de quiebras, la protección no existe y la residencia podrá responder en su día para 
pagar cualquier deuda que surja de estas circunstancias.

No obstante los beneficios que la Ley provee a la residencia familiar, lo cierto es que dicha protección limita el derecho propietario que una persona pueda tener en el hogar, principalmente aquellos que no disfrutan de su posesión. Por tanto, los miembros de una comunidad de bienes, como por ejemplo la compuesta por ex cónyuges o herederos, no podrán ejercer su derecho a liquidar su participación en la propiedad hasta tanto la protección de hogar seguro termine. De esta forma se detiene provisionalmente transacciones con dichos inmuebles con un impacto inmediato en las finanzas de sus titulares y en el flujo de transacciones comerciales.

Finalmente, en los casos donde el hogar seguro es irrenunciable, un acreedor estará imposibilitado de recuperar el crédito en mora mediante el embargo de la residencia familiar del deudor. Al observar que ocasionalmente el activo de mayor valor de una familia es su residencia, el acreedor queda generalmente desprovisto de propiedades a embargar y ejecutar. Por consiguiente, toda industria o negocio debe evaluar el efecto que pueda tener la figura de hogar seguro al ofrecer créditos no garantizados a individuos.

\section{Edwin R. Maldonado Medina}

\section{edwin.maldonado4@upr.edu}

BBA, J.D., Universidad de Puerto Rico; LL.M., Georgetown University Law Center. Catedrático Asociado de la Universidad de Puerto Rico, Recinto de Río Piedras, Facultad de Administración de Empresas; Profesor de Derecho Notarial y Sucesoral en la Escuela de Derecho, Universidad de Puerto Rico; Contador Público Autorizado. 